\title{
Digital Presence of a Research Center as a Research Dissemination Platform: Reach and Resources
}

Sarah E Lord, PhD; Katherine M Seavey, BA; Sonia D Oren, MEd; Alan J Budney, PhD; Lisa A Marsch, PhD

Center for Technology and Behavioral Health, Geisel School of Medicine, Dartmouth College, Lebanon, NH, United States

Corresponding Author:

Sarah E Lord, PhD

Center for Technology and Behavioral Health

Geisel School of Medicine

Dartmouth College

46 Centerra Parkway

Suite 315

Lebanon, NH, 03766

United States

Phone: 16036467079

Email: sarah.e.lord@dartmouth.edu

\begin{abstract}
Background: Web-based platforms can be powerful tools for research dissemination. By leveraging the advantages of mass media and interpersonal channels of communication, Web-based dissemination platforms may improve awareness about, and subsequent adoption of, evidence-based practices (EBPs). Digital dissemination strategies can augment traditional dissemination models, improving stakeholder access to digestible and actionable information and promoting translation of EBPs.

Objective: This study aimed to describe the reach and content of the Web presence of a National Institute on Drug Abuse Center of Excellence and how it is used to disseminate research related to digital behavioral health approaches.

Methods: The Center for Technology and Behavioral Health (CTBH) has a website and regularly updated Facebook and Twitter accounts. The website features include summaries of digital behavioral health approaches and related empirical literature, a blog feed focused on the state of the science and technology concerning digital health care approaches, and a newsletter about Center activities. We extracted website usage metrics from Google Analytics and follower counts from social media accounts for the period from March 1, 2013, to July 17, 2018.

Results: Since the implementation of analytic tracking, 70,331 users have initiated 96,995 sessions on the CTBH website. The website includes summaries of 86 digital therapeutic programs, encompassing 447 empirical articles. There are 1160 posts in the CTBH blog feed, including 180 summaries of scholarly articles. The Twitter and Facebook accounts have 577 and 1500 followers, respectively. The newsletter has reached a growing subscriber network and has a high open rate relative to industry standards.

Conclusions: The CTBH Web presence serves as a model for how to leverage accessible and easily updatable digital platforms as research dissemination channels. Digital dissemination tools can augment traditional dissemination strategies to promote awareness about evidence-based digital therapeutic approaches for behavioral health and health care more broadly.
\end{abstract}

(JMIR Ment Health 2019;6(4):e11686) doi: $\underline{10.2196 / 11686}$

\section{KEYWORDS}

telemedicine; internet; social media; behavioral sciences; implementation science; information dissemination

\section{Introduction}

\section{Background}

The limited translation of research to practice is a long-standing issue in health care [1-3], and adoption of innovations to support evidence-based treatment for substance use and mental health conditions is no exception. Barriers to translation include limited stakeholder awareness of evidence-based practices (EBP) and their demonstrated impact for target patient populations as well as clinician expectations that adoption of new practices may increase burden [4-6]. Strategies to make communication of research findings more relevant, digestible, and actionable to clinician and policy stakeholders may improve dissemination and adoption of empirically supported practices [7]. 


\section{The Promise of Digital Treatment Approaches to Substance Use and Mental Health Care}

Technology offers great promise for addressing many of the barriers to adoption of EBP [5,8]. Digital behavioral health approaches, such as Web-based programs, mobile apps, and text messaging, can transcend the time and geographic boundaries of traditional clinical practice settings and offer evidence-based care to broad patient audiences when and where they need it. Different mixed media (eg, text, audio, and video) can be used in digital therapeutic approaches to appeal to a broad range of learning styles [9] and promote engagement $[10,11]$. There is strong and growing evidence for digital therapeutic approaches targeting substance use and mental health conditions [12-17]. These digital behavioral health approaches have demonstrated efficacy for identifying symptoms [18,19], evoking positive behavior change [20-28], and facilitating recovery support [29]. Despite a promising impact, digital therapeutic approaches for behavioral health have yet to see widespread implementation in practice.

\section{Technology as a Platform for Research Dissemination}

Technology — and, in particular, the internet — can also serve as a powerful platform for science dissemination to patient, provider, researcher, and policy stakeholders. Digital platforms can bridge approaches to dissemination and diffusion of research, allowing information to reach broad audiences with little effort required from the researcher beyond posting the information. According to the diffusion of innovations theory [30], key dissemination channels include interpersonal and mass media channels of communication. Mass media channels of communication are the most efficient, but interpersonal communication channels are the most persuasive [30]. Web platforms may be able to leverage the strengths of both channels of communication. There is preliminary evidence that Web platforms share features of mass media (eg, reaching many people at once) and interpersonal channels of communication (eg, the ability to cultivate homophilous communities) [31]. Web-based platforms may fall into an entirely new channel of communication: new media, which shares the efficiency of mass media and personalization of interpersonal communication [32].

Studies have highlighted the internet, including social media, as a useful tool for researchers to disseminate information about EBPs to the public [33-36]. Websites related to research, such as blogs, can have higher traffic than Web-based journal articles about comparable topics [37]. Through digital media, research findings can be disseminated to broad audiences using language that is relevant and accessible, user-friendly, and integrated with social media to promote communication [34-36]. Such Web-based dissemination efforts can complement and extend dissemination of research via scientific publications; presentations to scientific, policy, and community audiences; and mass media coverage. To our knowledge, only 1 other study has described how an academic institutional website was used as a tool for research dissemination-in this case, focused on implementation of shared decision making in primary care [38].

Current initiatives by the National Institute on Drug Abuse (NIDA), the Substance Abuse and Mental Health Services Administration, and the Center for Substance Abuse Treatment focus on closing the science-to-practice gap through greater attention to the promotion of successful dissemination and implementation strategies for EBPs [39-41]. In this paper, we describe how website and social media features of a NIDA-designated P30 Center of Excellence (the Center for Technology and Behavioral Health [CTBH]) are used to disseminate research about digital therapeutic approaches for substance use and mental health conditions. Established in 2011, CTBH is a national and international leader in research focused on development, evaluation, dissemination, and implementation of digital behavioral health treatment approaches. CTBH maintains a website [42] as well as social media accounts to foster dissemination of research focused on digital behavioral health approaches and to promote awareness of CTBH activities and resources. The publicly available CTBH website and Facebook and Twitter accounts (collectively, CTBH Web presence) have the potential to reach broad audiences, including patients, clinicians, researchers, and policy makers.

Leveraging digital platforms for research knowledge translation has received little attention in translational research. Digital platforms can extend the reach of scientific knowledge to stakeholders who may not read academic journals [43]. Digital dissemination channels can allow for ready access to continuously updated information. Abundant and current content on a website promotes audience engagement [44]. Furthermore, posting about research on social media (eg, Twitter) facilitates uptake of research $[37,45,46]$. These digital channels are a key part of the mission of $\mathrm{CTBH}$ to be a national and international resource underscoring science-based digital behavioral health. The purpose of this paper was to present a model for leveraging digital platforms as research dissemination tools by describing CTBH's Web presence and presenting data about its content and reach.

\section{Methods}

\section{Center for Technology and Behavioral Health Web Presence}

CTBH maintains a center-specific website and Twitter and Facebook accounts to keep users informed about the state of the science regarding digital behavioral health approaches and CTBH activities. CTBH launched its website in May 2012. Screenshots of the website features are available in Multimedia Appendix 1. What follows is a brief description of the website content.

\section{The Center}

The Center is the gateway to pages listing CTBH leadership, members and affiliates, publications and presentations, active projects, hosted seminars, and announcements (eg, recruitment for research studies) and news stories about CTBH activities. Users can view and subscribe to the CTBH newsletter from this page.

\section{Program Review}

The Program Review is a filterable compendium of annotated summaries of empirical literature for specific digital approaches for the treatment of substance use disorders, co-occurring disorders, mental health conditions, and HIV. Programs are 
identified for review through scoping literature searches of academic databases for digital interventions targeting the aforementioned conditions. Literature for each program review is extracted from the searches, lists of works by the investigators, and bibliographies of relevant articles.

Program reviews include descriptions of each intervention and information about the target populations with which each intervention has been evaluated (eg, age, race, and gender), delivery method (eg, Web-based or mobile app), guiding theoretical models (eg, community reinforcement approach, cognitive behavior therapy, or self-regulation theory), intervention target (eg, substance use or depression), outcomes (eg, reduced substance use, abstinence, symptom severity, or treatment adherence), and languages and countries in which the intervention has been delivered and evaluated. Each program review includes summaries of the studies evaluating the digital therapeutic tool, including methodology, results, and implications, and citations for nonevaluation articles related to the program (eg, study protocols). The key characteristics identified in program reviews are associated with fostering successful implementation [47] and align with recent recommendations for standardization of reporting on digital therapeutic tools $[48,49]$. Users can filter programs by target age group, target substance or condition, type of program, and commercial availability. Program review summaries are updated monthly.

\section{Eye on Innovation}

Eye on Innovation is a blog-style newsfeed that includes links to, and excerpts from, news stories relating to recent developments in digital health and an annotated bibliography of recently published empirical literature related to emerging technology and health (Cutting Edge Literature). Content features are tagged to allow for easy filtering by users. The newsfeed is updated weekly.

\section{Social Media and Newsletter}

CTBH launched its Twitter account in September 2013 and Facebook account in August 2014. These accounts feature posts about news related to technology in behavioral health, innovative research, and updates about CTBH activities. The Twitter and Facebook accounts are updated at least daily. CTBH distributes a quarterly newsletter by email to a subscriber distribution list. Subscribers can join this list from the CTBH website or by signing up at CTBH-hosted events.

\section{Sources of Data}

We used Google Analytics to collect data on CTBH website usage. Information about social media audience is publicly displayed on the Facebook and Twitter accounts. We used information available from distribution service (MailChimp) reports to describe the audience and engagement with the newsletter over time.

\section{Data Extraction}

CTBH began using Google Analytics to track user activity on the website in March 2013. For this report, we extracted data from March 1, 2013, to July 17, 2018, on the number of users, number of sessions initiated, number of page views, percentage of sessions initiated by new users, average number of pages viewed per session, average time spent on the site per session, most viewed pages, and countries where users were located. Information about numbers of Twitter and Facebook followers and posts was extracted from the CTBH Facebook and Twitter accounts. We used newsletter reports to extract data about the number of people who received and opened the first (April 2012) and most recent (December 2017) electronic newsletters and about the number of newsletter subscribers over time.

\section{Results}

\section{Website Metrics}

Between March 1, 2013, and July 17, 2018, 70,331 users initiated 96,995 sessions on the CTBH website. About $72.50 \%$ $(70,317 / 96,995)$ of the sessions were initiated by new users. On average, users viewed about 2.4 pages per session and spent 1 min and 57 seconds on the site per session. Annual website usage metrics are available in Table 1 . The most popular pages were the homepage (29,113 views), The Center (11,644 views), and the Program Review landing pages $(10,826$ views; Table 2). Users most often viewed the website from the United States $(80.2 \%)$. Approximately $20 \%$ of the users were based in other countries (Table 3).

Table 1. Usage statistics for the Center for Technology and Behavioral Health website by year (March 1, 2013, to February 28, 2018).

\begin{tabular}{lllllll}
\hline Year $^{\mathrm{a}}$ & Visits & Users & Page views & $\begin{array}{l}\text { New user-initiated } \\
\text { sessions, n (\%) }\end{array}$ & $\begin{array}{l}\text { Average pages per } \\
\text { session }\end{array}$ & $\begin{array}{l}\text { Average time per } \\
\text { session }\end{array}$ \\
\hline $2013-2014$ & 9365 & 6364 & 34,230 & $6297(67.24)$ & 3.7 & $2: 57$ \\
$2014-2015$ & 17,383 & 12,379 & 48,035 & $12,198(70.17)$ & 2.8 & $2: 12$ \\
$2015-2016$ & 17,534 & 13,156 & 46,697 & $12,959(73.91)$ & 2.7 & $1: 57$ \\
$2016-2017$ & 17,062 & 12,130 & 52,779 & $11,983(70.23)$ & 3.1 & $2: 35$ \\
$2017-2018$ & 25,288 & 19,173 & 39,881 & $19,008(75.17)$ & 1.6 & $1: 18$ \\
Total (2013-2018) & 86,632 & 63,505 & 221,622 & $62,445(72.08)$ & 2.6 & $2: 03$ \\
\hline
\end{tabular}

${ }^{\mathrm{a}}$ Years begin on March 1st and end on the final day of February of the following year. 
Table 2. Most popular pages on the Center for Technology and Behavioral Health website based on page views (March 1, 2013, to July 17, 2018).

\begin{tabular}{ll}
\hline Page & Views (n) \\
\hline Home & 29,113 \\
The Center & 11,644 \\
Program Review & 10,826 \\
Center Director & 9654 \\
Center Members & 9465 \\
Active Projects & 6317 \\
Eye on Innovation & 5906 \\
Center Leadership & 5647 \\
Programs for Substance Use Disorders & 4354 \\
Center Highlights & 4257 \\
\hline
\end{tabular}

Table 3. Most common locations from which users access the Center for Technology and Behavioral Health website: number and percentage of sessions (March 1, 2013, to July 17, 2018).

\begin{tabular}{ll}
\hline Country & Sessions, n (\%) \\
\hline United States & $77,823(80.23)$ \\
Canada & $2514(2.59)$ \\
United Kingdom & $2026(2.09)$ \\
India & $1589(1.64)$ \\
Australia & $947(0.98)$ \\
\hline
\end{tabular}

\section{Program Review}

As of July 17, 2018, research related to 86 digital behavioral health therapeutic approaches were included in the Program Review. Within the 86 program reviews, there are 308 summaries of empirical studies evaluating the different digital behavioral health approaches and citations for 139 related articles (eg, secondary analyses). The most frequently viewed program review was Therapeutic Education System [21], a Web-based intervention for substance use based on the community reinforcement approach (4337 page views).

\section{Eye on Innovation and Cutting Edge Literature}

As of July 17, 2018, the Eye on Innovation feed contained 1160 posts, including 180 Cutting Edge Literature pieces. Tags for individual posts are extracted from a total of 171 tags. The most commonly used tags are mHealth (ie, an abbreviation for mobile health; 326 posts), mobile apps (262 posts), mental health (140 posts), substance use (129 posts), and policy and regulation (107 posts). The most frequently viewed post describes the Mobile App Rating Scale [50] (202 page views).

\section{Social Media and Newsletter}

CTBH has made 4849 tweets on the CTBH Twitter account since its creation. The Twitter account has 577 followers. As of July 17, 2018, there were 701 posts on the CTBH Facebook account. The Facebook page has been liked 1478 times and has 1500 followers.

The first newsletter in April 2012 was sent to 337 subscribers and was opened by $21 \%$ of the recipients. The most recent December 2017 newsletter was sent to 1132 subscribers and was opened by $34 \%$ of the recipients. The number of newsletter subscribers has increased each year since it has been recorded.

\section{Discussion}

\section{The Center for Technology and Behavioral Health Web Presence as a Dissemination Strategy}

The usage statistics associated with the CTBH Web presence indicate that the digital dissemination strategy was effective in reaching large audiences with research information related to digital therapeutics for behavioral health. Although users were primarily from the United States, about a quarter of users were based internationally. Although we were not able to determine user characteristics in this study, anecdotal evidence from email inquiries from the CTBH website from an array of stakeholders, including researchers, policy makers, clinicians, and patient consumers, suggests that we were able to reach diverse user audiences. To our knowledge, the only other study describing the reach of a Web-based research dissemination platform saw an average of 7906 visits by 5382 users each year [38]. The CTBH Web presence sees thousands of users and visits each year and has seen a growth in audience since its inception, suggesting a high and expanding reach of this digital dissemination strategy.

In addition, the CTBH website shows evidence of stickiness, commonly defined as a user's willingness to use and continue using a website [51,52]. An important metric of website stickiness is session duration. According to the Nielsen Group, users typically spend less than 1 min on a Web page, on average [53]. The average session duration on the $\mathrm{CTBH}$ website was 
$1 \mathrm{~min}$ and 57 seconds, indicating higher than average levels of stickiness. The CTBH newsletter has also seen a growing number of subscribers since its launch and has been consistently opened by a high percentage of subscribers. The open rate of the most recent newsletter (34\%) is impressive compared with the first newsletter in April 2012 (21\%) and with the industry average open rate (Education and Training: 22\%) [54]. The CTBH Twitter and Facebook accounts provide hundreds of followers with daily updates about digital behavioral health research.

The CTBH Web presence can serve as a model for research dissemination. Anecdotally, we have heard from researchers that they wish they could use their website more effectively for research dissemination. We present several features of the CTBH Web presence as a demonstration of the variety of ways websites and social media can be effectively leveraged to disseminate research. We also present the quantity of content on the CTBH website to illustrate the abundance of updated content continuously available to users.

Though the content on a website is not necessarily indicative of successful dissemination, user engagement is related to websites having enough content to attract repeat visitors and having current information [44]. Similarly, posts on social media are not necessarily indicative of successful research dissemination, but early evidence suggests that social media promotion or discussion of research may promote engagement with research. Notably, articles that were frequently linked in tweets were found to be 11 times more likely to be highly cited in academic publications than articles that were less frequently mentioned in tweets [45]. Similarly, Valdez Soto et al [46] identified a potential link between social media promotion and enrollment in Web-based training, and Hoang et al [37] found that above-average activity on Web-based articles coincided with social media promotion, though increases in engagement in either study could not be concretely linked to social media promotion.

The use of multiple digital dissemination channels (eg, website, social media, and electronic newsletter) provides users with greater flexibility in how they access information about the science of digital behavioral health therapeutic approaches. End users may choose to check the website for updates, receive quarterly newsletters, or follow CTBH social media accounts for daily updates. The growing audiences on the website and followers on social media accounts demonstrate the success of the model for promoting reach and awareness about research related to digital therapeutic approaches. We hope that by describing the features of the CTBH Web presence, we can help other researchers to optimize their own Web presence for research dissemination to attract and engage user audiences.

\section{Limitations and Future Directions}

One limitation of this study is that we did not conduct statistical analyses comparing website use with users' actual use of evidence-based digital behavioral health approaches in practice or research. Evaluating the impact of this research dissemination model on user behavior is an important direction for future research. Another limitation is that we could not examine the early growth of website usage because Google Analytics was not implemented for the site until the year after its launch. In addition, usage data from Google Analytics did not allow us to get a detailed picture of those who viewed the website, including professions of users and whether users were affiliated with CTBH or from outside of the CTBH network. Future features of the Web presence will include metrics to assess user characteristics.

The data extracted from the CTBH social media accounts only offer a current picture of user interaction with the accounts; we were unable to extract historical usage data for the accounts. Finally, it is also relevant to mention that spam accounts on social media, although relatively infrequent, can distort user interaction statistics [55]. It may be difficult to identify spam accounts from a list of followers. Although some spam account behavior is markedly different from the behavior of legitimate accounts, other spam accounts display patterns of interaction similar to the behavior of legitimate accounts [56].

Future directions for the CTBH website as a research dissemination platform include expansion of existing features and addition of features to encourage interaction among users of the CTBH Web presence components. A Resources page of the website was introduced in 2017, which includes a developing compendium of measures for assessing implementation of digital therapeutic interventions across the stages of treatment development research continuum [57] and roadmaps for implementation of digital behavioral health therapeutic approaches in different care settings. Future resources will include Web-based consent protocols and best practice methods for research study participant recruitment on social media. CTBH plans to engage its audience through social media to promote conversation among user stakeholders about interests and experiences with digital behavioral health approaches, with the goal of fostering collaborations for future implementation studies.

CTBH aims to continue to disseminate timely information about the state of digital approaches to behavioral health and will further explore the potential of social media to personalize the digital dissemination experience. There is limited research on the role of new media as facilitators in the translation of research to practice. We have demonstrated that our digital dissemination strategy has achieved a good reach to end user stakeholders compared with other published work [38]. We plan to investigate the persuasiveness of this approach for promoting the use and adoption of digital therapeutics in future work.

\section{Conclusions}

In this paper, we demonstrated the potential of digital strategies to successfully disseminate information about research related to digital behavioral health therapeutic approaches. Although Web presence can promote awareness about existing research, successful translation depends on the application of knowledge and implementation skills to promote the use of these digital approaches by patients-clients, providers, and researchers [58]. In future research, we will examine how stakeholders utilize information from the CTBH digital dissemination platforms. We will also explore strategies for using these platforms to promote collaboration among stakeholder groups to promote 
research agendas focused on the successful implementation of digital behavioral health approaches in diverse settings.

\section{Acknowledgments}

This research is supported by the CTBH, a P30 Center of Excellence funded by NIDA (P30: \#5P30DA029926-05; PI: LM). The authors would like to thank Fort Point Design for their work in developing and maintaining the CTBH website and associated features.

\section{Conflicts of Interest}

None declared.

\section{Multimedia Appendix 1}

Screenshots of the Center for Technology and Behavioral Health Web presence features. Images were extracted on July $23,2018$.

[PDF File (Adobe PDF File), 6MB-Multimedia Appendix 1]

\section{References}

1. Rychetnik L, Bauman A, Laws R, King L, Rissel C, Nutbeam D, et al. Translating research for evidence-based public health: key concepts and future directions. J Epidemiol Community Health 2012 Dec;66(12):1187-1192. [doi:

10.1136/jech-2011-200038] [Medline: 22569750]

2. Spoth R, Rohrbach LA, Greenberg M, Leaf P, Brown CH, Fagan A, Society for Prevention Research Type 2 Translational Task Force Members Contributing Authors. Addressing core challenges for the next generation of type 2 translation research and systems: the translation science to population impact (TSci Impact) framework. Prev Sci 2013 Aug;14(4):319-351 [FREE Full text] [doi: 10.1007/s11121-012-0362-6] [Medline: 23430579]

3. Shidhaye R, Lund C, Chisholm D. Closing the treatment gap for mental, neurological and substance use disorders by strengthening existing health care platforms: strategies for delivery and integration of evidence-based interventions. Int $\mathbf{J}$ Ment Health Syst 2015;9:40 [ FREE Full text] [doi: 10.1186/s13033-015-0031-9] [Medline: 26719762]

4. Aarons GA, Wells RS, Zagursky K, Fettes DL, Palinkas LA. Implementing evidence-based practice in community mental health agencies: a multiple stakeholder analysis. Am J Public Health 2009 Nov;99(11):2087-2095. [doi: 10.2105/AJPH.2009.161711] [Medline: 19762654]

5. Powell BJ, Hausmann-Stabile C, McMillen JC. Mental health clinicians' experiences of implementing evidence-based treatments. J Evid Based Soc Work 2013 Oct;10(5):396-409. [doi: 10.1080/15433714.2012.664062] [Medline: 24066630]

6. Aarons GA, Cafri G, Lugo L, Sawitzky A. Expanding the domains of attitudes towards evidence-based practice: the evidence based practice attitude scale-50. Adm Policy Ment Health 2012 Sep;39(5):331-340 [FREE Full text] [doi: 10.1007/s10488-010-0302-3] [Medline: 20607597]

7. Tabak RG, Padek MM, Kerner JF, Stange KC, Proctor EK, Dobbins MJ, et al. Dissemination and Implementation Science Training Needs: Insights From Practitioners and Researchers. Am J Prev Med 2017 Mar;52(3S3):S322-S329 [FREE Full text] [doi: 10.1016/j.amepre.2016.10.005] [Medline: 28215389]

8. Thompson DS, O'Leary K, Jensen E, Scott-Findlay S, O'Brien-Pallas L, Estabrooks CA. The relationship between busyness and research utilization: it is about time. J Clin Nurs 2008 Feb;17(4):539-548. [doi: 10.1111/j.1365-2702.2007.01981.x] [Medline: 18205684]

9. Mankey VL. Using multimodal and multimedia tools in the psychiatric education of diverse learners: examples from the mental status exam. Acad Psychiatry 2011;35(5):335-339. [doi: 10.1176/appi.ap.35.5.335] [Medline: 22007095]

10. Milward J, Drummond C, Fincham-Campbell S, Deluca P. What makes online substance-use interventions engaging? A systematic review and narrative synthesis. Digit Health 2018;4:2055207617743354 [FREE Full text] [doi: 10.1177/2055207617743354] [Medline: 29942622]

11. Ballew P, Castro S, Claus J, Kittur N, Brennan L, Brownson RC. Developing web-based training for public health practitioners: what can we learn from a review of five disciplines? Health Educ Res 2013 Apr;28(2):276-287 [FREE Full text] [doi: 10.1093/her/cys098] [Medline: 22987862]

12. Marsch LA, Borodovsky JT. Technology-based interventions for preventing and treating substance use among youth. Child Adolesc Psychiatr Clin N Am 2016 Dec;25(4):755-768 [FREE Full text] [doi: 10.1016/j.chc.2016.06.005] [Medline: $\underline{27613350}]$

13. Marsch LA, Dallery J. Advances in the psychosocial treatment of addiction: the role of technology in the delivery of evidence-based psychosocial treatment. Psychiatr Clin North Am 2012 Jun;35(2):481-493 [FREE Full text] [doi: 10.1016/j.psc.2012.03.009] [Medline: 22640767]

14. Noar SM, Black HG, Pierce LB. Efficacy of computer technology-based HIV prevention interventions: a meta-analysis. AIDS 2009 Jan 2;23(1):107-115. [doi: 10.1097/QAD.0b013e32831c5500] [Medline: 19050392] 
15. Watson T, Simpson S, Hughes C. Text messaging interventions for individuals with mental health disorders including substance use: A systematic review. Psychiatry Res 2016 Dec 30;243:255-262. [doi: 10.1016/j.psychres.2016.06.050] [Medline: 27423123]

16. Sugarman DE, Campbell ANC, Iles BR, Greenfield SF. Technology-based interventions for substance use and comorbid disorders: an examination of the emerging literature. Harv Rev Psychiatry 2017;25(3):123-134 [FREE Full text] [doi: 10.1097/HRP.0000000000000148] [Medline: 28475504]

17. Mohr DC, Burns MN, Schueller SM, Clarke G, Klinkman M. Behavioral intervention technologies: evidence review and recommendations for future research in mental health. Gen Hosp Psychiatry 2013 Aug;35(4):332-338 [FREE Full text] [doi: 10.1016/j.genhosppsych.2013.03.008] [Medline: 23664503 ]

18. Butler SF, Budman SH, Goldman RJ, Newman FL, Beckley KE, Trottier D, et al. Initial validation of a computer-administered Addiction Severity Index: the ASI-MV. Psychol Addict Behav 2001 Mar;15(1):4-12. [Medline: 11255937]

19. Lord SE, Trudeau KJ, Black RA, Lorin L, Cooney E, Villapiano A, et al. CHAT: development and validation of a computer-delivered, self-report, substance use assessment for adolescents. Subst Use Misuse 2011;46(6):781-794. [doi: 10.3109/10826084.2010.538119] [Medline: 21174498]

20. Budney AJ, Stanger C, Tilford JM, Scherer EB, Brown PC, Li Z, et al. Computer-assisted behavioral therapy and contingency management for cannabis use disorder. Psychol Addict Behav 2015 Sep;29(3):501-511 [FREE Full text] [doi: 10.1037/adb0000078] [Medline: 25938629]

21. Campbell AN, Nunes EV, Matthews AG, Stitzer M, Miele GM, Polsky D, et al. Internet-delivered treatment for substance abuse: a multisite randomized controlled trial. Am J Psychiatry 2014 Jun;171(6):683-690 [FREE Full text] [doi: 10.1176/appi.ajp.2014.13081055] [Medline: 24700332]

22. Carroll KM, Ball SA, Martino S, Nich C, Babuscio TA, Nuro KF, et al. Computer-assisted delivery of cognitive-behavioral therapy for addiction: a randomized trial of CBT4CBT. Am J Psychiatry 2008 Jul;165(7):881-888 [FREE Full text] [doi: 10.1176/appi.ajp.2008.07111835] [Medline: 18450927]

23. Carroll KM, Ball SA, Martino S, Nich C, Babuscio TA, Rounsaville BJ. Enduring effects of a computer-assisted training program for cognitive behavioral therapy: a 6-month follow-up of CBT4CBT. Drug Alcohol Depend 2009 Feb 1;100(1-2):178-181 [FREE Full text] [doi: 10.1016/j.drugalcdep.2008.09.015] [Medline: 19041197]

24. Carroll KM, Kiluk BD, Nich C, Gordon MA, Portnoy GA, Marino DR, et al. Computer-assisted delivery of cognitive-behavioral therapy: efficacy and durability of CBT4CBT among cocaine-dependent individuals maintained on methadone. Am J Psychiatry 2014 Apr;171(4):436-444 [FREE Full text] [doi: 10.1176/appi.ajp.2013.13070987] [Medline: 24577287]

25. Kay-Lambkin FJ, Baker AL, Kelly B, Lewin TJ. Clinician-assisted computerised versus therapist-delivered treatment for depressive and addictive disorders: a randomised controlled trial. Med J Aust 2011 Aug 01;195(3):S44-S50. [Medline: $\underline{21806518]}$

26. Kay-Lambkin FJ, Baker AL, Lewin TJ, Carr VJ. Computer-based psychological treatment for comorbid depression and problematic alcohol and/or cannabis use: a randomized controlled trial of clinical efficacy. Addiction 2009 Mar;104(3):378-388. [doi: 10.1111/j.1360-0443.2008.02444.x] [Medline: 19207345]

27. Marsch LA, Guarino H, Acosta M, Aponte-Melendez Y, Cleland C, Grabinski M, et al. Web-based behavioral treatment for substance use disorders as a partial replacement of standard methadone maintenance treatment. J Subst Abuse Treat 2014 Jan;46(1):43-51 [FREE Full text] [doi: 10.1016/j.jsat.2013.08.012] [Medline: 24060350]

28. Ondersma SJ, Svikis DS, Thacker LR, Beatty JR, Lockhart N. Computer-delivered screening and brief intervention (e-SBI) for postpartum drug use: a randomized trial. J Subst Abuse Treat 2014 Jan;46(1):52-59 [FREE Full text] [doi: 10.1016/j.jsat.2013.07.013] [Medline: 24051077]

29. Gustafson DH, McTavish FM, Chih MY, Atwood AK, Johnson RA, Boyle MG, et al. A smartphone application to support recovery from alcoholism: a randomized clinical trial. JAMA Psychiatry 2014 May;71(5):566-572 [FREE Full text] [doi: 10.1001/jamapsychiatry.2013.4642] [Medline: 24671165]

30. Rogers E. Diffusion of Innovations. 5th Edition. New York, NY: Free Press; 2003.

31. Rolls K, Hansen M, Jackson D, Elliott D. How health care professionals use social media to create virtual communities: an integrative review. J Med Internet Res 2016 Dec 16;18(6):e166 [FREE Full text] [doi: 10.2196/jmir.5312] [Medline: 27328967]

32. Sundstrom B. Mothers "Google It Up:" Extending Communication Channel Behavior in Diffusion of Innovations Theory. Health Commun 2016;31(1):91-101. [doi: 10.1080/10410236.2014.936339] [Medline: 26075413]

33. Fitzgerald RT, Radmanesh A. Social media and research visibility. AJNR Am J Neuroradiol 2015 Apr;36(4):637 [FREE Full text] [doi: 10.3174/ajnr.A4054] [Medline: 25034775]

34. Duffy M. The Internet as a research and dissemination resource. Health Promot Int 2000;15(4):349-353. [doi: 10.1093/heapro/15.4.349]

35. Choo EK, Ranney ML, Chan TM, Trueger NS, Walsh AE, Tegtmeyer K, et al. Twitter as a tool for communication and knowledge exchange in academic medicine: a guide for skeptics and novices. Med Teach 2015 May;37(5):411-416. [doi: 10.3109/0142159X.2014.993371] [Medline: 25523012] 
36. Bernhardt JM, Mays D, Kreuter MW. Dissemination 2.0: closing the gap between knowledge and practice with new media and marketing. J Health Commun 2011;16(Suppl 1):32-44. [doi: 10.1080/10810730.2011.593608] [Medline: 21843094]

37. Hoang J, McCall J, Dixon A, Fitzgerald R, Gaillard F. Using social media to share your radiology research: how effective is a blog post? J Am Coll Radiol 2015 Jul;12(7):760-765. [doi: 10.1016/j.jacr.2015.03.048] [Medline: 25959491]

38. Hébert J, Robitaille H, Turcotte S, Légaré F. Online dissemination strategies of a Canada Research Chair: overview and lessons learned. JMIR Res Protoc 2017 Feb 24;6(2):e27 [FREE Full text] [doi: 10.2196/resprot.6413] [Medline: 28235751]

39. Condon TP, Miner LL, Balmer CW, Pintello D. Blending addiction research and practice: strategies for technology transfer. J Subst Abuse Treat 2008 Sep;35(2):156-160. [doi: 10.1016/j.jsat.2007.09.004] [Medline: 18337054]

40. Martino S, Brigham GS, Higgins C, Gallon S, Freese TE, Albright LM, et al. Partnerships and pathways of dissemination: the National Institute on Drug Abuse-Substance Abuse and Mental Health Services Administration Blending Initiative in the Clinical Trials Network. J Subst Abuse Treat 2010 Jun;38(Suppl 1):S31-S43 [FREE Full text] [doi:

10.1016/j.jsat.2009.12.013] [Medline: 20307793]

41. Addiction Technology Transfer Center (ATTC) Network Technology Transfer Workgroup. Research to practice in addiction treatment: key terms and a field-driven model of technology transfer. J Subst Abuse Treat 2011 Sep;41(2):169-178. [doi: 10.1016/j.jsat.2011.02.006] [Medline: 21466943]

42. Center for Technology and Behavioral Health. URL: http://www.c4tbh.org/ [accessed 2018-07-19] [WebCite Cache ID 711n3ASMf]

43. Weisz $\mathrm{J}, \mathrm{Ng}$ M, Bearman S. Odd couple? Reenvisioning the relation between science and practice in the dissemination-implementation era. Clin Psychol Sci 2013 Dec 11;2(1):58-74. [doi: 10.1177/2167702613501307]

44. Garett R, Chiu J, Zhang L, Young S. A literature review: website design and user engagement. Online J Commun Media Technol 2016 Jul;6(3):1-14 [FREE Full text] [Medline: 27499833]

45. Eysenbach G. Can tweets predict citations? Metrics of social impact based on Twitter and correlation with traditional metrics of scientific impact. J Med Internet Res 2011 Dec 19;13(4):e123 [FREE Full text] [doi: 10.2196/jmir.2012] [Medline: 22173204]

46. Valdez Soto SM, Balls-Berry J, Bishop S, Aase L, Timimi F, Montori V, et al. Use of web 2.0 social media platforms to promote community-engaged research dialogs: a preliminary program evaluation. JMIR Res Protoc 2016 Sep 09;5(3):e183 [FREE Full text] [doi: 10.2196/resprot.4808] [Medline: 27613231]

47. Bewick BM, Ondersma SJ, Høybye MT, Blakstad O, Blankers M, Brendryen H, et al. Key intervention characteristics in e-Health: steps towards standardized communication. Int J Behav Med 2017 Dec;24(5):659-664 [FREE Full text] [doi: 10.1007/s12529-016-9630-3] [Medline: 28405917]

48. Eysenbach G, CONSORT-EHEALTH Group. CONSORT-EHEALTH: improving and standardizing evaluation reports of Web-based and mobile health interventions. J Med Internet Res 2011 Dec 31;13(4):e126 [FREE Full text] [doi: 10.2196/jmir.1923] [Medline: 22209829]

49. Proudfoot J, Klein B, Barak A, Carlbring P, Cuijpers P, Lange A, et al. Establishing guidelines for executing and reporting Internet intervention research. Cogn Behav Ther 2011;40(2):82-97. [doi: 10.1080/16506073.2011.573807] [Medline: 25155812]

50. Stoyanov SR, Hides L, Kavanagh DJ, Zelenko O, Tjondronegoro D, Mani M. Mobile app rating scale: a new tool for assessing the quality of health mobile apps. JMIR Mhealth Uhealth 2015 Mar 11;3(1):e27 [FREE Full text] [doi: 10.2196/mhealth.3422] [Medline: 25760773]

51. Furner C, Racherla P, Babb J. Mobile app stickiness (MASS) and mobile interactivity: a conceptual model. Mark Rev 2014 Aug 11;14(2):163-188. [doi: 10.1362/146934714X14024778816913]

52. Lin JJ. Online stickiness: its antecedents and effect on purchasing intention. Behav Inform Technol 2007 Nov;26(6):507-516. [doi: 10.1080/01449290600740843]

53. Nielsen J. Nielsen Norman Group. How long do users stay on web pages? URL: https://www.nngroup.com/articles/ how-long-do-users-stay-on-web-pages/ [accessed 2018-05-03] [WebCite Cache ID 6z8tBRoi7]

54. MailChimp. 2017. Average email campaign stats of MailChimp customers by industry URL: https://mailchimp.com/ resources/email-marketing-benchmarks/ [accessed 2018-05-03] [WebCite Cache ID 6z8t7iQAA]

55. Gilani Z, Farahbakhsh R, Crowcroft J. Do Bots impact Twitter activity? In: Proceedings of the 26th International Conference on World Wide Web Companion. Geneva, Switzerland: International World Wide Web Conferences Steering Committee; 2017 Presented at: 26th International Conference on World Wide Web Companion; April 03-07, 2017; Perth, Australia URL: https://dl.acm.org/citation.cfm?id=3041021.3054255 [doi: 10.1145/3041021.3054255]

56. Almaatouq A, Alabdulkareem A, Nouh M, Shmueli E, Alsaleh M, Singh VK, et al. Twitter: who gets caught? observed trends in social micro-blogging spam. In: Proceedings of the 2014 ACM conference on Web science. 2014 Presented at: ACM conference on Web science; June 23-26, 2014; Bloomington, Indiana, USA p. 23-26. [doi: 10.1145/2615569.2615688]

57. Onken LS, Carroll KM, Shoham V, Cuthbert BN, Riddle M. Reenvisioning clinical science: unifying the discipline to improve the public health. Clin Psychol Sci 2014 Jan 01;2(1):22-34 [FREE Full text] [doi: 10.1177/2167702613497932] [Medline: 25821658] 
58. Proctor E, Silmere H, Raghavan R, Hovmand P, Aarons G, Bunger A, et al. Outcomes for implementation research: conceptual distinctions, measurement challenges, and research agenda. Adm Policy Ment Health 2011 Mar;38(2):65-76 [FREE Full text] [doi: 10.1007/s10488-010-0319-7] [Medline: 20957426]

\section{Abbreviations \\ CTBH: The Center for Technology and Behavioral Health \\ EBP: evidence-based practice \\ NIDA: The National Institute on Drug Abuse}

Edited by G Eysenbach; submitted 24.07.18; peer-reviewed by C Ronquillo, B Cotner; comments to author 21.09.18; revised version received 18.01.19; accepted 23.01.19; published 05.04.19

Please cite as:

Lord SE, Seavey KM, Oren SD, Budney AJ, Marsch LA

Digital Presence of a Research Center as a Research Dissemination Platform: Reach and Resources

JMIR Ment Health 2019;6(4):e11686

URL: https://mental.jmir.org/2019/4/e11686/

doi: $10.2196 / 11686$

PMID: 30950800

(C) Sarah E Lord, Katherine M Seavey, Sonia D Oren, Alan J Budney, Lisa A Marsch. Originally published in JMIR Mental Health (http://mental.jmir.org), 05.04.2019. This is an open-access article distributed under the terms of the Creative Commons Attribution License (https://creativecommons.org/licenses/by/4.0/), which permits unrestricted use, distribution, and reproduction in any medium, provided the original work, first published in JMIR Mental Health, is properly cited. The complete bibliographic information, a link to the original publication on http://mental.jmir.org/, as well as this copyright and license information must be included. 